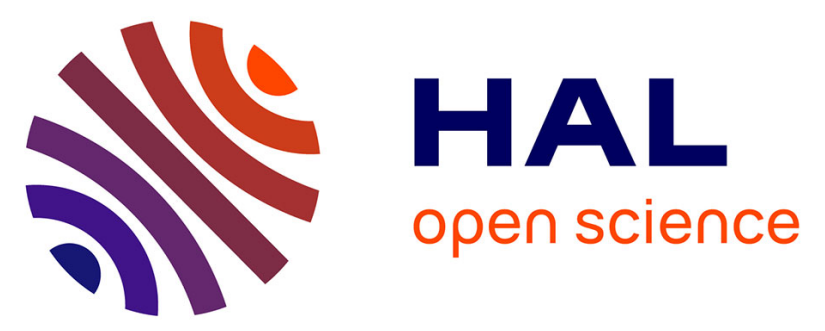

\title{
Coagulase-negative Staphylococcus bacteraemia accounts for one third of Staphylococcus bacteraemia in a French university hospital
}

Yohan N'Guyen, Sonia Baumard, Véronique Vernet-Garnier, Anne Sophie Batalla, Christophe de Champs, Roland Jaussaud, Christophe Strady

\section{To cite this version:}

Yohan N'Guyen, Sonia Baumard, Véronique Vernet-Garnier, Anne Sophie Batalla, Christophe de Champs, et al.. Coagulase-negative Staphylococcus bacteraemia accounts for one third of Staphylococcus bacteraemia in a French university hospital. Scandinavian Journal of Infectious Diseases, 2011, 44, pp.79 - 85. 10.3109/00365548.2011.617777 . hal-03266968

\section{HAL Id: hal-03266968 \\ https://hal.univ-reims.fr/hal-03266968}

Submitted on 22 Jun 2021

HAL is a multi-disciplinary open access archive for the deposit and dissemination of scientific research documents, whether they are published or not. The documents may come from teaching and research institutions in France or abroad, or from public or private research centers.
L'archive ouverte pluridisciplinaire HAL, est destinée au dépôt et à la diffusion de documents scientifiques de niveau recherche, publiés ou non, émanant des établissements d'enseignement et de recherche français ou étrangers, des laboratoires publics ou privés. 


\title{
Coagulase-negative Staphylococcus bacteraemia accounts for one third of Staphylococcus bacteraemia in a French university hospital
}

\author{
YOHAN N'GUYEN ${ }^{1}$, SONIA BAUMARD ${ }^{1}$, VÉRONIQUE VERNET-GARNIER ${ }^{2}$, \\ ANNE SOPHIE BATALLA ${ }^{1}$, CHRISTOPHE DE CHAMPS ${ }^{2}$, ROLAND JAUSSAUD ${ }^{1} \&$ \\ CHRISTOPHE STRADY ${ }^{1}$
}

From the ${ }^{1}$ Service de Médecine Interne et Maladies Infectieuses, and ${ }^{2}$ Laboratoire de Bactériologie-Virologie-Hygiène, Hôpital Robert Debré, CHU Reims, France

\begin{abstract}
Background: We sought to determine the epidemiological patterns of Staphylococcus bacteraemia, with a focus on the proportion of coagulase-negative Staphylococcus (CoNS) as compared to Staphylococcus aureus bacteraemia, and the prognosis. Methods: All patients with significant Staphylococcus bacteraemia at the university hospital in Reims in 2008 were included in the study. Data were retrieved retrospectively from the patient records using a standardized case investigation form. Quantitative variables were compared using the Mann-Whitney $U$-test and qualitative variables were compared using Fisher's exact test or Pearson's Chi-square test, as appropriate. Bivariate logistic regression was performed on both $\mathrm{S}$. aureus and CoNS bacteraemia. All variables with a $p$-value of $<0.15$ were entered into a multiple logistic regression model. Results: CoNS represented $31.6 \%$ of all strains isolated. The methicillin resistance rate was higher in CoNS (66.1\%) than in S. aureus $(19.1 \%)(p<0.0001)$. CoNS were more frequently associated with intravascular catheters and neoplastic disease, whereas S. aureus was associated with chronic renal failure $(p<0.0001)$ and diabetes mellitus $(p=0.004)$. Mortality was $30.7 \%$ for S. aureus and $19.6 \%$ for CoNS bacteraemia $(p=0.12)$. Methicillin resistance was not associated with mortality $(p=0.99)$. Factors independently associated with mortality in CoNS and S. aureus bacteraemia were age and acute renal failure. The presence of severe sepsis/septic shock was only associated with mortality in S. aureus bacteraemia. Conclusions: CoNS represent one third of Staphylococcus bacteraemia. The mortality difference between CoNS and $\mathrm{S}$. aureus bacteraemia was not statistically significant. Acute renal failure is associated with mortality in both S. aureus and CoNS bacteraemia.
\end{abstract}

Keywords: Bacteraemia, coagulase-negative Staphylococcus, epidemiology, acute renal failure

\section{Introduction}

There are numerous reports of infections due to methicillin-resistant Staphylococcus aureus (MRSA) in the USA [1,2]. The prevalence of MRSA is very different in Europe, with extreme differences between countries and facilities: from $2 \%$ [3] to $43 \%$ [4] of all Staphylococcus aureus bacteraemia.

The incidence of infective endocarditis (IE) due to $S$. aureus is also increasing [5], as well as the incidence of IE due to coagulase-negative Staphylococcus (CoNS) in the USA [6] and in Europe [7].

New anti-staphylococcal treatments have been developed because of the emergence of severe infections due to MRSA and because of reports of vancomycin treatment failure $[8,9]$.

CoNS are known to be frequently less sensitive to vancomycin than S. aureus [10], but the prognosis for CoNS appears better than for S. aureus in meningitis [11,12] and endocarditis [7]. Little data exist comparing the mortality of CoNS bacteraemia with $S$. aureus bacteraemia [13], and the predictive factors for mortality are less well known in CoNS bacteraemia [14] than in S. aureus bacteraemia $[15,16]$. No predictive factors of complicated CoNS bacteraemia have been identified, although they have been investigated for $S$. aureus bacteraemia $[17,18]$.

Correspondence:Y. N'Guyen, Service de Médecine Interne et Maladies Infectieuses, Hôpital Robert Debré, Avenue Général Koenig, 51100 Reims, France. Tel: +33 3267894 22. Fax: +33 3267840 90. E-mail: yohan.nguyen@wanadoo.fr 
We sought to determine the epidemiological patterns of Staphylococcus bacteraemia, with an emphasis on the proportion of CoNS bacteraemia as compared to $\mathrm{S}$. aureus bacteraemia, and the prognosis of CoNS bacteraemia.

\section{Methods}

\section{Materials}

This study was conducted retrospectively in 2008 in a 1549-bed university hospital in Reims, France. All patients with significant bacteraemia in the adult surgery, medicine, and intensive care units (926 beds) were included. A significant bacteraemia was defined in the presence of 1 blood culture positive for S. aureus. For CoNS, bacteraemia was considered significant when criterion 2 of the definition of a laboratory-confirmed bloodstream infection as per the US National Nosocomial Infections Surveillance System and the National Healthcare Safety Network [2] was fulfilled (e.g. fever and 2 blood cultures drawn on separate occasions positive for CoNS, or fever and 1 blood culture from a central line positive for CoNS, with favourable outcome under appropriate antimicrobial therapy and no other argument for infection at another site).

\section{Blood culture processing}

Blood culture bottles were incubated on the BacT/ ALERT 3D system (bioMérieux, Marcy l'Etoile, France). Positive bottles containing Gram-positive cocci in clusters were inoculated onto $\mathrm{S}$. aureus ID select agar (SAID; bioMérieux) and sheep blood agar plates (Oxoid, Dardilly, France). After 18-24 h incubation at $37^{\circ} \mathrm{C}$, bacterial colonies were further tested using the catalase test (bioMérieux), the Pastorex test (Bio-Rad, Marnes-la-Coquette, France), and the Vitek2 (bioMérieux) microbial identification system.

All bacterial growth identified on blood agar plates was further examined using antimicrobial susceptibility testing by the disk diffusion method, performed with an inoculum of $10^{6} \mathrm{CFU} / \mathrm{ml}$ on Mueller-Hinton agar plates, in accordance with the recommendations of the Antibiogram Committee of the French Microbiology Society (CA-SFM) [19].

Detection of the mec $A$ gene was performed using a polymerase chain reaction (PCR) as the methicillin resistance gold standard for all strains isolated.

Vancomycin minimum inhibitory concentrations (MICs) were determined by E-test method (bioMérieux) following the manufacturer's instructions.

\section{Data collection}

Demographic, epidemiological, clinical, and laboratory data were recovered retrospectively from the patient records, using a standardized case investigation form.

\section{Definitions}

Comorbidity corresponded to the presence of a pre-existing ongoing illness.

Immunodepression was defined as the presence of a primary or secondary immune deficiency (human immunodeficiency virus infection, solid organ transplant, malignant neoplasm treated or not, autoimmune disease, immunosuppressive agent, diabetes mellitus, renal insufficiency, liver cirrhosis, asplenia, obesity, under-nutrition, and chronic alcoholism).

Foreign material was defined as the presence of osteosynthesis material, an orthopaedic or valvular prosthesis, pace-maker device, central venous catheter, implantable chamber, surgical wound drain device, or urinary catheter.

The Charlson weighted comorbidity index and the criteria for sepsis, severe sepsis, and septic shock have been detailed elsewhere [20,21].

A bacteraemia was nosocomial when it occurred more than $48 \mathrm{~h}$ after admission. Healthcare-related bacteraemia has been defined elsewhere [22]. All other bacteraemia was community-acquired.

Intravascular catheter-related infection has been defined elsewhere [23].

A secondary site of infection corresponded to the presence of another site of infection due to the same Staphylococcus species, remote from the primary site of infection. Septic thrombosis was included as a secondary site of infection.

IE was defined using the modified Duke criteria [24].

All in-hospital deaths were attributed to the Staphylococcus bacteraemia.

Acute renal failure was defined as a $50 \%$ increase in the serum baseline creatinine level.

\section{Statistical analysis}

Quantitative variables were compared using the Mann-Whitney $U$-test and qualitative variables were compared using Fisher's exact test or Pearson's Chi-square test, as appropriate.

Bivariate logistic regression was performed on both $S$. aureus and CoNS bacteraemia. All variables with a $p$-value of $<0.15$ were entered into a multiple logistic regression model. Statistical analyses were performed using Statview 5.0 software (SAS institute).

\section{Results}

Incidence

Two hundred and seven significant Staphylococcus bacteraemia episodes were observed in patients 
hospitalized in the adult surgery, medicine, and intensive care units of the university hospital of Reims in 2008, giving an incidence of Staphylococcus bacteraemia of 2.74 per 1000 admissions. The incidence density was 0.77 per 1000 patient-days. One hundred and twenty-four episodes of bacteraemia were diagnosed in medicine units $(59.9 \%), 51$ in surgery units $(24.6 \%)$, and 32 in intensive care units $(15.5 \%)$.

\section{Population characteristics}

Patient records were unavailable for 6 patients. Population $(n=201)$ characteristics are shown in Table I. The most frequently retrieved sources of infection were intravascular catheters $(58.3 \%)$, skin and soft tissues $(17.9 \%)$, and surgical site infections $(11.2 \%)$. The most frequent secondary sites of infection were osteoarticular (43.2\%), septic thrombosis $(35.2 \%)$, and cerebral emboli $(8.1 \%)$.

\section{Bacteriology}

Two hundred and six Staphylococcus strains were isolated from 201 patients. CoNS represented 31.6\% of all strains; the incidence of CoNS bacteraemia was 0.86 per 1000 admissions and the incidence density was 0.23 per 1000 patient-days. Of the CoNS, Staphylococcus epidermidis was the most frequently isolated species $(90.7 \%)$. Staphylococcus warneri, Staphylococcus capitis, Staphylococcus haemolyticus, and Staphylococcus hominis accounted for the remaining $9.3 \%$.

Thirty-four percent of Staphylococcus isolates were methicillin-resistant. The methicillin resistance rate was higher in CoNS (66.1\%) than in S. aureus $(19.1 \%) \quad(p<0.0001)$. Vancomycin MICs were determined only for 53 Staphylococcus strains (Table II). Sixty percent of S. aureus strains tested and $96.9 \%$ of CoNS strains tested had a vancomycin MIC of $2 \mathrm{mg} / \mathrm{l}$ or more. The median vancomycin MIC was $2 \mathrm{mg} / 1$.

\section{Outcome}

The in-hospital mortality was $27.3 \%(n=55)$. One hundred and forty patients experienced S. aureus bacteraemia and 43 died during hospitalization. The mortality rate was $30.7 \%$ for S. aureus bacteraemia. Factors significantly associated with mortality in S. aureus bacteraemia are shown in Table III.

Sixty-one patients experienced CoNS bacteraemia and 12 died during hospitalization (missing data $=1$ ), giving a mortality rate of $19.6 \%$. The difference

Table I. Population characteristics of the 201 patients who experienced Staphylococcus aureus and coagulase-negative Staphylococcus (CoNS) bacteraemia.

\begin{tabular}{|c|c|c|c|}
\hline & S. aureus & CoNS & $p$-Value \\
\hline Number of patients (\%) & $140(100 \%)$ & $61(100 \%)$ & \\
\hline Male & $97(69.2 \%)$ & $45(73.7 \%)$ & 0.52 \\
\hline Comorbidity & $134(95.7 \%)$ & $60(98.3 \%)$ & $0.67^{\mathrm{a}}$ \\
\hline Immunodepression & $113(80.7 \%)$ & $50(81.9 \%)$ & 0.83 \\
\hline Charlson weighted index of comorbidity $>3$ & $83(59.2 \%)$ & $24(39.3 \%)$ & 0.009 \\
\hline Cardiac valvulopathy & $39(27.8 \%)$ & $24(39.3 \%)$ & 0.10 \\
\hline Foreign material & $63(45.0 \%)$ & $36(59.0 \%)$ & 0.06 \\
\hline Intravenous drug user & $3(2.1 \%)$ & $1(1.6 \%)$ & $0.99^{\mathrm{a}}$ \\
\hline Haematology ward hospitalization & $5(3.5 \%)$ & $25(40.9 \%)$ & $<0.0001$ \\
\hline Neoplasm antecedent & $37(26.4 \%)$ & $38(62.3 \%)$ & $<0.0001$ \\
\hline Chronic kidney disease antecedent & $53(37.8 \%)$ & $3(4.9 \%)$ & $<0.0001$ \\
\hline Diabetes mellitus antecedent & $54(38.5 \%)$ & $11(18.0 \%)$ & 0.004 \\
\hline Mean age (range), y & $67.3(22-96)$ & $61.2(16-86)$ & 0.008 \\
\hline Mean Charlson weighted index of comorbidity (range) & $3.34(0-11)$ & $2.72(0-10)$ & 0.08 \\
\hline Mean creatinine at time of admission ${ }^{\mathrm{b}}$ (range), $\mu \mathrm{mol} / 1$ & $154.6(23-672)$ & $87.3(29-311)$ & 0.01 \\
\hline Community-acquired & $21(15.0 \%)$ & $8(13.1 \%)$ & 0.72 \\
\hline Healthcare-related & $35(25.0 \%)$ & $12(19.7 \%)$ & \\
\hline Nosocomial & $84(60.0 \%)$ & $41(67.2 \%)$ & \\
\hline Presence of septic shock or severe sepsis criteria & $26(18.5 \%)$ & $5(8.2 \%)$ & 0.06 \\
\hline Definite source of bacteraemia & $104(74.2 \%)$ & $47(77.0 \%)$ & 0.67 \\
\hline Catheter as a source of bacteraemia & $35(25.0 \%)$ & $40(65.5 \%)$ & $<0.0001$ \\
\hline Skin infection as a source of bacteraemia & $27(19.2 \%)$ & $1(1.6 \%)$ & 0.0009 \\
\hline Secondary site of infection & $26(18.5 \%)$ & $11(18.0 \%)$ & 0.92 \\
\hline Infective endocarditis (IE) & $6(4.3 \%)$ & $5(8.2 \%)$ & $0.31^{\mathrm{a}}$ \\
\hline
\end{tabular}

${ }^{\text {a}}$ Fisher's exact test.

${ }^{b}$ Data missing for 20 patients. 
Table II. Vancomycin median minimum inhibitory concentration (MIC) for the 53 Staphylococcus strains tested in 2008.

\begin{tabular}{lcrr}
\hline & Number of strains & Vancomycin median MIC (mg/l) & Vancomycin MIC range mg/l \\
\hline Staphylococcus & 53 & 2 & $0.75-4$ \\
Methicillin-resistant strains & 41 & 2 & $0.75-4$ \\
Staphylococcus aureus & 20 & 2 & $0.75-2$ \\
MSSA & 8 & 1.5 & $1-2$ \\
MRSA & 12 & 2 & $0.75-2$ \\
CoNS & 33 & 2 & $1.5-4$ \\
MSCoNS & 4 & 2.5 & $2-3$ \\
MRCoNS & 29 & 2 & $1.5-4$ \\
\hline
\end{tabular}

MSSA, methicillin-sensitive Staphylococcus aureus; MRSA, methicillin-resistant Staphylococcus aureus; CoNS, coagulase-negative Staphylococcus; MSCoNS, methicillin-sensitive coagulase-negative Staphylococcus; MRCoNS, methicillin-resistant coagulase-negative Staphylococcus.

between CoNS and S. aureus mortality did not reach significance $(p=0.12)$. Factors significantly associated with mortality in CoNS bacteraemia are shown in Table III.

The multiple logistic regression model is shown in Table IV.

\section{Discussion}

CoNS were found to represent one third of all Staphylococcus bacteraemia in the Reims hospital. This rate is important because there is no consensus concerning the management of CoNS bacteraemia. CoNS are always among the 4 most frequently isolated pathogens in bloodstream infections [25-28], but there are great differences between European countries. Another study from France [25], a country where the MRSA prevalence is high according to the European Antimicrobial Resistance Surveillance System (EARSS) data, reported a higher incidence of CoNS than S. aureus bacteraemia during the period 2005-2007. The definition of CoNS bacteraemia was not the same as that used in the present study, and the CoNS bacteraemia incidence was probably overestimated because skin contaminants were considered as genuine bacteraemia. A nationwide study from Finland [26], which is a country with a low prevalence of MRSA, reported an equal incidence of CoNS and S. aureus bacteraemia; however, the incidence of CoNS increased above that of $S$. aureus when only nosocomial bloodstream infections were taken into account [27]. Such data have been reported by Bourneton and colleagues [25], but we were not able to demonstrate a difference between the incidence of CoNS and S. aureus in nosocomial bacteraemia in our study. Finally, a recent nationwide study in England [28] reported that CoNS bacteraemia has constantly increased in incidence as compared to $S$. aureus bacteraemia since 2006, which suggests a major change in the epidemiology of Staphylococcus bacteraemia. Such data should be confirmed using a strict definition of CoNS bacteraemia [2].

Table III. Factors associated with mortality among patients experiencing Staphylococcus bacteraemia.

\begin{tabular}{|c|c|c|c|c|c|c|c|c|}
\hline \multirow[b]{2}{*}{ Factor } & \multicolumn{4}{|c|}{ Staphylococcus aureus } & \multicolumn{4}{|c|}{ Coagulase-negative Staphylococcus } \\
\hline & $\begin{array}{l}\text { Deceased } \\
\text { patients } \\
(n=43)\end{array}$ & $\begin{array}{l}\text { Survivors } \\
(n=97)\end{array}$ & $\begin{array}{c}\text { Missing } \\
\text { data }\end{array}$ & $p$-Value & $\begin{array}{l}\text { Deceased } \\
\text { patients } \\
(n=12)\end{array}$ & $\begin{array}{l}\text { Survivors } \\
(n=48)\end{array}$ & $\begin{array}{c}\text { Missing } \\
\text { data }\end{array}$ & $p$-Value \\
\hline Age, $y$ & 74.9 & 63.9 & 0 & 0.001 & 70.7 & 58.8 & 0 & 0.01 \\
\hline $\begin{array}{l}\text { Charlson weighted index } \\
\text { of comorbidity } \geq 3\end{array}$ & $30 / 43(69.7 \%)$ & $53 / 97(54.6 \%)$ & 0 & 0.09 & $6 / 12(50.0 \%)$ & $18 / 48(37.5 \%)$ & 1 & $0.51^{\mathrm{a}}$ \\
\hline Community-acquired & $8 / 43(18.6 \%)$ & $13 / 97(13.4 \%)$ & 0 & 0.42 & $1 / 12(8.3 \%)$ & $7 / 48(14.6 \%)$ & 1 & $0.99^{\mathrm{a}}$ \\
\hline $\begin{array}{l}\text { Presence of a secondary } \\
\text { site of infection }\end{array}$ & $11 / 43(25.6 \%)$ & $15 / 97(15.4 \%)$ & 0 & 0.15 & $2 / 12(16.6 \%)$ & $9 / 48(18.7 \%)$ & 1 & $0.99^{\mathrm{a}}$ \\
\hline $\begin{array}{l}\text { Presence of infective } \\
\text { endocarditis (IE) }\end{array}$ & $3 / 43(6.9 \%)$ & $3 / 97(3.1 \%)$ & 0 & $0.37^{\mathrm{a}}$ & $2 / 12(16.6 \%)$ & $3 / 48(6.2 \%)$ & 1 & $0.25^{\mathrm{a}}$ \\
\hline $\begin{array}{l}\text { No definite source of } \\
\text { bacteraemia }\end{array}$ & $16 / 43(37.2 \%)$ & $20 / 97(20.6 \%)$ & 0 & 0.038 & $3 / 12(25.0 \%)$ & $10 / 48(20.8 \%)$ & 1 & $0.71^{\mathrm{a}}$ \\
\hline Severe sepsis/septic shock & $14 / 43(32.5 \%)$ & $12 / 97(12.3 \%)$ & 0 & 0.004 & $1 / 12(8.3 \%)$ & $4 / 48(8.3 \%)$ & 1 & $0.99^{\mathrm{a}}$ \\
\hline Acute renal failure & $28 / 42(66.6 \%)$ & $36 / 96(37.5 \%)$ & 2 & 0.001 & $9 / 12(75.0 \%)$ & $17 / 48(35.4 \%)$ & 1 & 0.01 \\
\hline Methicillin resistance & $10 / 43(23.2 \%)$ & $17 / 97(17.5 \%)$ & 0 & 0.42 & $9 / 12(75.0 \%)$ & $33 / 48(68.7 \%)$ & 1 & 0.67 \\
\hline
\end{tabular}

${ }^{\text {a}}$ Fisher's exact test. 
Table IV. Factors significantly associated with mortality in the logistic regression model. ${ }^{a}$

\begin{tabular}{lccc}
\hline & & & Multivariate analysis \\
\cline { 2 - 3 } Staphylococcus aureus + CoNS & $\begin{array}{c}\text { Bivariate analysis } \\
p \text {-Value }\end{array}$ & OR & $95 \%$ CI \\
\hline Age & $<0.0001$ & 1.04 & $1.01-1.07$ \\
Charlson weighted index of comorbidity $\geq 3$ & 0.038 & 1.06 & $0.51-2.24$ \\
Community acquired & 0.64 & & 0.001 \\
Presence of secondary site of infection & 0.25 & & 0.86 \\
Presence of infective endocarditis (IE) & 0.18 & 1.81 & $0.83-3.96$ \\
No definite source of bacteraemia & 0.04 & 3.02 & $1.25-7.28$ \\
Severe sepsis/septic shock & 0.006 & 3.06 & $0.13-6.25$ \\
Acute renal failure & 0.0001 & 0.86 & $0.38-1.95$ \\
CoNS species & 0.12 & & 0.002 \\
Methicillin resistance & 0.99 & & 0.71 \\
\hline
\end{tabular}

CoNS, coagulase-negative Staphylococcus; OR, odds ratio; CI, confidence interval.

${ }^{a}$ The Hosmer and Lemeshow goodness of fit test gives $p=0.39$.

The main limitations of this study are that it was carried out at a single centre and that the data were collected retrospectively, which may explain the low rate of IE and secondary sites of infection. The inclusion criteria for CoNS were very strict and we may have missed genuine cases of CoNS bacteraemia with only 1 positive blood culture.

\section{Population characteristics}

Patients experiencing CoNS bacteraemia were younger, had lower creatinine on admission, and less frequently had a Charlson weighted comorbidity index over 3 than patients with S. aureus bacteraemia. However, the Charlson weighted comorbidity index has not been validated for CoNS bacteraemia. The presence of an indwelling catheter is more frequently noted among patients with CoNS bacteraemia. CoNS are known for their pathogenesis in catheter-related infections [29]. The presence of an indwelling catheter is probably the reason why CoNS were more frequently isolated in the haematology ward and in patients with neoplasms in our study.

\section{Bacteriology}

S. epidermidis was the most frequently isolated CoNS, as previously reported [6]. CoNS were found to represent more than half of the methicillin-resistant strains in our facility. The methicillin resistance rate in S. aureus was only $19 \%$. This value is far higher than the $2 \%$ rate reported in the study by Kaech et al. [3], but lower than the $43 \%$ rate in the study by Libert et al. [4]. This means that in our facility, methicillin class penicillin should be the reference treatment for $80 \%$ of the strains of S. aureus isolated. Methicillin class penicillin has been proven superior to vancomycin in methicillin-sensitive S. aureus (MSSA) bacteraemia $[16,30]$. There are no similar data available for CoNS bacteraemia.
Despite a very small sample size, the vancomycin MICs were far higher in our hospital than those reported from different countries. Seventy-five percent of MRSA had a vancomycin $M I C \geq 2 \mathrm{mg} / 1$ $(n=9 / 12)$, which is far higher than the rates of $9.7 \%$ $(n=9 / 92)$ [8] and 22.2\% $(n=92 / 414)$ [9] reported in the literature. This means that the majority of our patients with MRSA bacteraemia are potentially at risk of vancomycin failure [8,9]. In this situation some authors suggest an increase in the dosage of vancomycin, as has been recommended in pneumonia [31]. However a high dosage vancomycin regimen exposes the patient to an increased risk of nephrotoxicity [32-34] and is not always associated with a better outcome [35]. In this situation, the new anti-staphylococcal drugs should be considered [36-38]. Ninety-six percent of methicillin-resistant CoNS had a vancomycin MIC of $\geq 2 \mathrm{mg} / 1(n=28 / 29)$, which is also well above the rate of $53.3 \%$ found by Jones $(n=3148 / 5902)$ [10]. There are no specific data available concerning the management of such CoNS bacteraemia.

All these data concerning vancomycin MICs should be interpreted with caution: vancomycin MICs were determined for only 53 strains, because routine vancomycin MIC determination was not fully implemented in 2008. Thus too many data were missing, and taking into account vancomycin MICs when establishing risk factors for mortality would have been a selection bias.

\section{Outcome}

The in-hospital mortality rate was $30 \%$ for S. aureus bacteraemia as reported by Chang et al. [18]. Age, the presence of severe sepsis or septic shock, and the presence of acute renal failure have previously been reported [3] as risk factors for mortality in S. aureus bacteraemia. However, we used a different definition 
of acute renal failure: a $50 \%$ increase in serum creatinine in our study versus an only $20 \%$ increase in the study of Kaech et al. [3]. A Charlson weighted index of comorbidity of $\geq 3$ was not significantly associated with mortality in our study. This may be due to a sampling bias. Methicillin resistance was also not associated with mortality during S. aureus bacteraemia. Some of the studies included in the meta-analysis by Cosgrove and colleagues [15] found a similar result, however the pooled odds ratio was 1.93 (95\% confidence interval (CI) 1.54-2.42) when MRSA and MSSA bacteraemia mortality were compared.

The in-hospital mortality was $19.6 \%$ for CoNS in our study. Data in the literature concerning mortality for CoNS bacteraemia show that mortality varies between $4.9 \%$ and $28 \%[39,40]$.

CoNS bacteraemia was found not to be significantly associated with a lower mortality when compared with S. aureus $(p=0.12)$, and CoNS species does not appear to be a predictive factor of mortality in our multivariate analysis combining S. aureus and CoNS bacteraemia. Data in the literature comparing the mortality from CoNS and that from S. aureus bacteraemia are scarce. Danese and colleagues [13] reported an odds ratio of 0.8 (95\% CI 0.66-0.94) when comparing mortality due to CoNS and mortality due to $S$. aureus bacteraemia in haemodialysis patients. However, there were no differences in the in-hospital mortality between CoNS and S. aureus native valve endocarditis [6].

The factors associated with mortality among patients with CoNS bacteraemia are very different from those observed in S. aureus bacteraemia. Only age and acute renal failure were found to be common to S. aureus and CoNS bacteraemia. The presence of severe sepsis or septic shock was not found to be correlated with mortality in CoNS bacteraemia in our study, and we did not confirm the results obtained by Topeli and colleagues [14]. The deleterious role of acute renal failure in CoNS bacteraemia has only been reported once, in a study focusing on CoNS endocarditis [7].

In the multivariate analysis, CoNS were pooled with S. aureus and CoNS species was tested in that model. Multivariate analysis with patients experiencing CoNS bacteraemia only was not performed because of the relatively small number of patient deaths in CoNS bacteraemia. Factors independently associated with mortality in CoNS bacteraemia should be determined in studies with larger sample sizes.

This article provides data on the specific epidemiological features observed in our hospital, with a high proportion of CoNS bacteraemia (one third of all Staphylococcus bacteraemia). The CoNS strains were more frequently methicillin-resistant. A high vancomycin $\mathrm{MIC}$ of $>2 \mathrm{mg} / \mathrm{l}$ was frequently observed among tested strains.
The mortality rate was not statistically lower in CoNS bacteraemia when compared to $S$. aureus bacteraemia. Acute renal failure was found to be associated with mortality in both S. aureus and CoNS bacteraemia. More studies are needed concerning prognostic factors and the management of CoNS bacteraemia, as previously done for S. aureus [35,38].

\section{Acknowledgements}

We thank the following Professors and Doctors, and their secretariat, for allowing us access to the medical records: Prof. S. Backchine, Prof. B. Baehrel, Dr A. Bazin, Prof. P. Bernard, Prof. F. Blanchard, Prof. A. Chays, Prof. C. Clement, Prof. E. Dehoux, Prof. J. F. Delattre, Prof. B. Delemer, Prof. A. Delmer, Prof. J. P. Eschard, Prof. F. Lebargy, Prof. A. Leon, Prof. D. Metz, Prof. J. L. Pennaforte, Prof. P. Rieu, Prof. P. Rousseaux, Prof. F. Staerman, Prof. G. Thieffin.

Declaration of interest: The authors declare that they have no conflict of interest.

\section{References}

[1] Kallen AJ, Mu Y, Bulens S, Reingold A, Petit S, Gershman K. Health care-associated invasive MRSA infections, 2005-2008. JAMA 2010;304:641-8.

[2] Burton DC, Edwards JR, Horan TC, Jernigan JA, Fridkin SK. Methicillin-resistant Staphylococcus aureus central line-associated bloodstream infections in US intensive care units, 1997-2007. JAMA 2009;301:727-36.

[3] Kaech C, Elzi L, Sendi P, Frei R, Laifer G, Bassetti S. Course and outcome of Staphylococcus aureus bacteraemia: a retrospective analysis of 308 episodes in a Swiss tertiary care centre. Clin Microbiol Infect 2006;12:345-52.

[4] Libert M, Elkhoti M, Massaut J, Karmali R, Mascart G, Cherifi S. Risk factors for meticillin resistance and outcome of Staphylococcus aureus bloodstream infection in a Belgian university hospital. J Hosp Infect 2008;68:17-24.

[5] Fowler VG, Miro JM, Hoen B, Cabell CH, Abrutyn E, Rubinstein E. Staphylococcus aureus endocarditis: a consequence of medical progress. JAMA 2005;293:3012-21.

[6] Chu VH, Woods CW, Miro JM, Hoen B, Cabell CH, Pappas PA. Emergence of coagulase-negative staphylococci as a cause of native valve endocarditis. Clin Infect Dis 2008; $46: 232-42$.

[7] Haro JL, Lomas JM, Plata A, Ruiz J, Gálvez J, de la Torre J. Left-sided native valve endocarditis by coagulase-negative staphylococci: an emerging disease. Enferm Infecc Microbiol Clin 2008;26:263-8.

[8] Lodise TP, Graves J, Evans A, Graffunder E, Helmecke M, Lomaestro BM. Relationship between vancomyin MIC and failure among patients with methicillin-resistant Staphylococcus aureus bacteremia treated with vancomycin. Antimicrob Agents Chemother 2008;52:3315-20.

[9] Soriano A, Marco F, Martínez JA, Pisos E, Almela M, Dimova VP. Influence of vancomycin minimum inhibitory concentration on the treatment of methicillin-resistant Staphylococcus aureus bacteremia. Clin Infect Dis 2008; 46:193-200. 
[10] Jones RN. Microbiological features of vancomycin in the 21 st century. Minimum inhibitory concentration creep, bactericidal/static activity and applied breakpoints to predict clinical outcomes or detect resistant strains. Clin Infect Dis 2006;42:S13-24.

[11] Chang WN, Lu CH, Huang CR, Chuang YC, Tsai NW, Chen SF. Epidemiology of adult staphylococcal meningitis in southern Taiwan: a clinical comparison of Staphylococcus aureus infection and coagulase-negative staphylococcal infection. Jpn J Infect Dis 2007;60: 262-6.

[12] Laguna-Del Estal P, Castaneda-Pastor A, Gil-Navarro M, Garcia-Madero R, Lopez-Cano Gomez M, Agud-Fernandez M. Comparative study of meningitis due to Staphylococcus aureus and coagulase-negative staphylococci in adults. Rev Neurol 2009;48:2-6.

[13] Danese MD, Griffiths RI, Dylan M, Yu HT, Dubois R, Nissenson AR. Mortality differences among organisms causing septicemia in hemodialysis patients. Hemodial Int 2006; 10:56-62.

[14] Topeli A, Unal S, Hayran M, Akalin HE. Septic shock as a predictor of mortality in bacteremia caused by coagulasenegative staphylococci. Eur J Clin Microbiol Infect Dis 1997; 16:411-6.

[15] Cosgrove SE, Sakoulas G, Perencevich EN, Schwaber MT, Karchmer AW, Carmeli Y. Comparison of mortality associated with methicillin-resistant and methicillin-susceptible Staphylococcus aureus bacteremia: a meta-analysis. Clin Infect Dis 2003;36:53-9.

[16] Lodise TP, McKinnon PS, Levine DP, Rybak MJ. Impact of empirical-therapy selection on outcomes of intravenous drug users with infective endocarditis caused by methicillinsusceptible Staphylococcus aureus. Antimicrob Agents Chemother 2007;51:3731-3.

[17] Fowler VG, Olsen MK, Corey GR, Woods CW, Cabell CH, Reller LB. Clinical identifiers of complicated Staphylococcus aureus bacteremia. Arch Intern Med 2003;163:2066-72.

[18] Chang FY, MacDonald BB, Peacock JE Jr, Musher DM, Triplett P, Mylotte JM. A prospective multicenter study of Staphylococcus aureus bacteremia: incidence of endocarditis, risk factors for mortality and clinical impact of methicillin resistance. Medicine (Baltimore) 2003;82:322-32.

[19] Comite de L'antibiogramme de la Societe Francaise de Microbiologie. Recommandations 2010 (Edition de Janvier 2010) Copyright 2010 - Société Française de Microbiologie Coordonnateur: Pr C.J. SOUSSY Centre Hospitalier Universitaire Henri Mondor 94010 Creteil Cedex http://www. sfm-microbiologie.org/Userfiles/file/CASFM/casfm_2010. pdf accessed 22/09/2011.

[20] Lesens O, Methlin C, Hansmann Y, Remy V, Martinot M, Bergin C. Role of comorbidity in mortality related to Staphylococcus aureus bacteremia: a prospective study using the Charlson weighted index of comorbidity. Infect Control Hosp Epidemiol 2003;24: 890-6.

[21] Levy M, Fink M, Marshall JC, Abraham E, Angus D, Cook D. $2001 \mathrm{SCCM} / \mathrm{ESICM} / \mathrm{ACCP} / \mathrm{ATS} / \mathrm{SIS}$ International Sepsis Definitions Conference. Intensive Care Med 2003;29:530-8.

[22] Lesens O, Hansmann Y, Brannigan E, Hopkins S, Meyer P, O'Connel B. Healthcare-associated Staphylococcus aureus bacteremia and the risk for methicillin resistance: is the Centers for Disease Control and Prevention definition for community-acquired bacteremia still appropriate? Infect Control Hosp Epidemiol 2005;26: 204-9.

[23] Mermel LA, Farr BM, Sherertz RJ, Raad II, O'Grady N, Harris JS. Guidelines for the management of intravascular catheter-related infections. Clin Infect Dis 2001;32:1249-72.

[24] Li JS, Sexton DJ, Mick N, Nettles R, Fowler VG, Ryan T. Proposed modifications to the Duke criteria for the diagnosis of infective endocarditis. Clin Infect Dis 2000;30:633-8.
CoNS bacteraemia in a French university hospital

[25] Bourneton O, Mutel T, Heranney D, Hernandez C, Lavigne T, Waller J. Incidence of hospital-acquired and communityacquired bloodstream infections in the University of Strasbourg Hospital, France, between 2005 and 2007. Pathol Biol (Paris) 2010;58:29-34.

[26] Skogberg K, Lyytikäinen O, Ruutu P, Ollgren J, Nuorti JP. Increase in bloodstream infections in Finland, 1995-2002. Epidemiol Infect 2008;136:108-14.

[27] Lyytikäinen O, Lumio J, Sarkkinen H, Kolho E, Kostiala A, Ruutu P. Nosocomial bloodstream infections in Finnish Hospitals during 1999-2000. Clin Infect Dis 2002;35: e14-9.

[28] Wilson J, Elgohari S, Livermore DM, Cookson B, Johnson A, Lamagni $\mathrm{T}$. Trends among pathogens reported as causing bacteraemia in England, 2004-2008. Clin Microbiol Infect 2011;17:451-8.

[29] Von Eiff C, Peters G, Heilmann C. Pathogenesis of infections due to coagulase-negative staphylococci. Lancet Infect Dis 2002;2:677-85.

[30] Chang FY, Peacock JE Jr, Musher DM, Triplett P, MacDonald BB, Mylotte JM. Recurrence and the impact of antibiotic treatment in a prospective multicenter study. Medicine (Baltimore) 2003;82:333-9.

[31] Moise-Broder PA, Forrest A, Birmingham MC, Schentag JJ. Pharmacodynamics of vancomycin and other antimicrobials in patients with Staphylococcus aureus lower respiratory tract infections. Clin Pharmacokinet 2004;43: 925-42.

[32] Hidayat LK, Hsu DI, Quist R, Shriner KA, Wong-Beringer A. High-dose vancomycin therapy for methicillin-resistant Staphylococcus aureus infections. Efficacy and toxicity. Arch Intern Med 2006;166:2138-44.

[33] Lodise TP, Lomaestro BM, Graves J, Drusano GL. Larger vancomycin doses (at least four grams per day) are associated with an increased incidence of nephrotoxicity. Antimicrob Agents Chemother 2008;52:1330-6.

[34] Lodise TP, Patel N, Lomaestro BM, Rodvold KA, Drusano GL. Relationship between initial vancomycin concentration-time profile and nephrotoxicity among hospitalized patients. Clin Infect Dis 2009;49:507-14.

[35] Jeffres MN, Isakow W, Doherty JA, McKinnon PS, Ritchie DJ, Micek ST. Predictors of mortality for methicillin-resistant Staphylococcus aureus health-care-associated pneumonia. Chest 2006;130:947-55.

[36] Wunderink R, Rello J, Cammarata SK, Croos-Dabrera R, Kollef $\mathrm{MH}$. Linezolid vs vancomycin: analysis of two doubleblind studies of patients with methicillin-resistant Staphylococcus aureus nosocomial pneumonia. Chest 2003;124: 1789-97.

[37] Rehm SJ, Boucher H, Levine D, Campion M, Eisenstein BI, Vigliani GA. Daptomycin versus vancomycin plus gentamicin for treatment of bacteraemia and endocarditis due to Staphylococcus aureus: subset analysis of patients infected with methicillin-resistant isolates. J Antimicrob Chemother 2008; 62:1413-21.

[38] Rybak MJ, Lomaestro BM, Rotschafer JC, Moellering RC, Craig WA, Billeter M. Vancomycin therapeutic guidelines: a summary of consensus recommendations from the Infectious Diseases Society of America, the American Society of HealthSystem Pharmacists, and the Society of Infectious Diseases Pharmacists. Clin Infect Dis 2009;49:325-7.

[39] Thylefors JD, Harbarth S, Pittet D. Increasing bacteremia due to coagulase-negative staphylococci: fiction or reality? Infect Control Hosp Epidemiol 1998;19:581-9.

[40] Favre B, Hugonnet S, Correa L, Sax H, Rohner P, Pittet D. Nosocomial bacteremia: clinical significance of a single blood culture positive for coagulase-negative staphylococci. Infect Control Hosp Epidemiol 2005;26:697-702. 